\section{The Ocean Takes a Deep Breath}

\author{
Arne Körtzinger,* Jens Schimanski, Uwe Send, Douglas Wallace
}

The temperature $(T)$ and salinity $(S)$ of the deep ocean are established at mid- and high latitudes where intermediate and deep waters are formed through subduction and deep convection. These processes also ventilate the deep ocean for atmospheric gases such as oxygen $\left(\mathrm{O}_{2}\right)$. Although $\mathrm{O}_{2}$ is consumed within the ocean by heterotrophic processes, the ocean has no internal oxygen sources. The $\mathrm{O}_{2}$ concentration in the ocean's interior therefore reflects a balance between supply through circulation and loss through respiration.

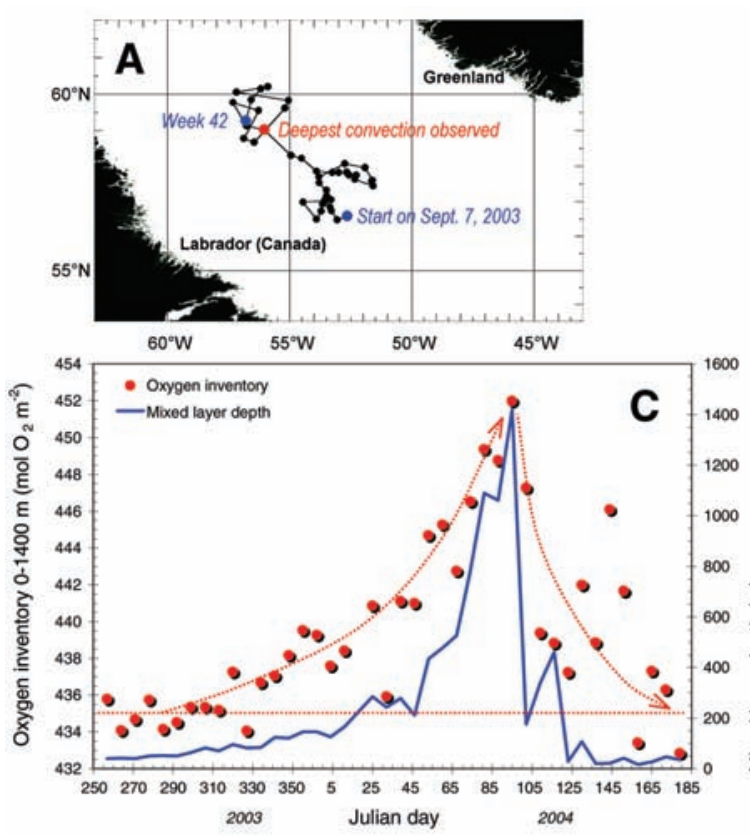

Fig. 1. (A) Float track in the central Labrador Sea Gyre, showing positions of weekly surfacing between deployment on 7 September 2003 and profile 42 on 26 June 2004. (B) Selected vertical oxygen profiles. (C) Temporal development of the oxygen inventory (in the upper $1400 \mathrm{~m}$ ) and mixed-layer depth, based on 42 weeks of measurements. Dotted red lines represent the build-up and decay of the oxygen inventory in the convection region relative to an assumed background concentration of the surrounding waters.
Long-term trends and variability in atmosphere-ocean $\mathrm{O}_{2}$ flux complicate the use of atmospheric oxygen time series for global carbon budgeting (1). Modeling studies (2) have linked flux variations to variability in winter convection. Observations (3) of temporal trends in intermediate water $\mathrm{O}_{2}$ concentrations have been explained by changing ocean ventilation. Models (4) also suggest that the air-to-sea $\mathrm{O}_{2}$ flux will decrease in response to changes in ocean circulation. Monitoring of oceanic oxygen could therefore provide important constraints on the global carbon cycle, as well as a means to monitor changes in ocean circulation.

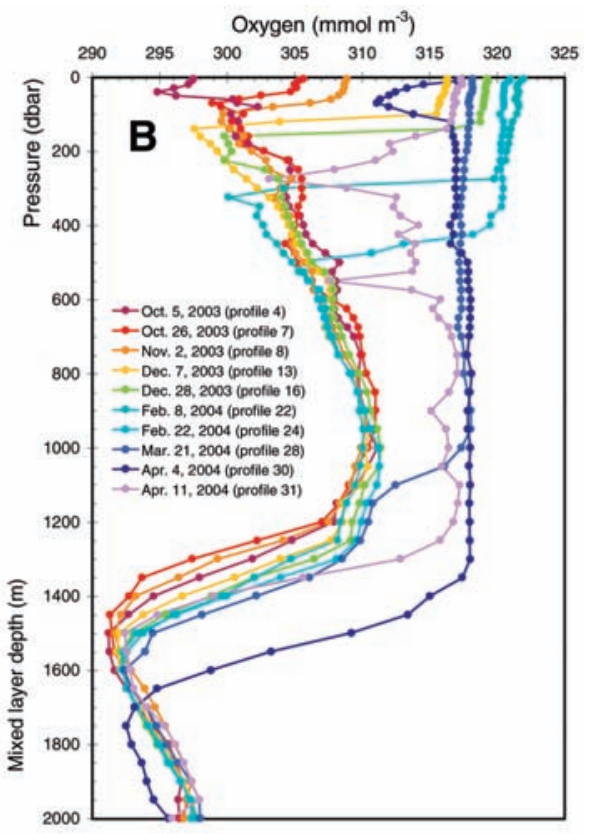

We therefore conducted a test deployment of an oxygen sensor mounted on an autonomous profiling float (5). Such floats, which report their data by satellite, are being deployed in large numbers (there are presently nearly 1500 ) to monitor the $T$ and $S$ structure of the oceans. $\mathrm{O}_{2}$ measurements from such floats could provide tens of thousands of profiles in a single year, a multiple of all data from the unprecedented, 10-year, ship-based World Ocean Circulation Experiment of the 1990 s.

change was associated with an inventory increase in the upper $1400 \mathrm{~m}$ of $17 \mathrm{~mol}$ of $\mathrm{O}_{2} \mathrm{~m}^{-2}$ (Fig. 1C), which corresponds to monthly air-to-sea fluxes of up to $7 \mathrm{~mol}$ of $\mathrm{O}_{2} \mathrm{~m}^{-2}$. Such fluxes strongly exceed those previously reported for the subpolar North Atlantic (7). The oxygen intake was mostly driven by the progressive, almost exponential, deepening of the mixed layer (Fig. 1C), which progressively exposed large volumes of undersaturated water to the atmosphere.

This "deep breath" of a high-latitude deep convection region was observed "live via satellite." The inhalation of oxygen stopped in early April (profile 30), when deep convection ceased. Afterward, the homogeneously mixed volume was rapidly capped by a shallow low-salinity surface layer and sealed from the atmosphere. Subsequently, lateral intrusions into the newly formed water introduced spike-like signatures that likely represent characteristics of water from outside the convection region. The rapid decrease of the $\mathrm{O}_{2}$ inventory after convection is striking. Outgassing can be ruled out as a major cause. Rather, it appears that the newly added oxygen is rapidly injected into the ocean interior through lateral export of the convectively mixed water and replacement with less oxygenated surrounding waters.

Our results suggest that new observational platforms and sensors could make oxygen a key parameter for addressing major issues of global change research during the 21 st century.

References and Notes

1. R. F. Keeling, S. C. Piper, M. Heimann, Nature 381, 218 (1996).

2. G. A. McKinley, M. J. Follows, J. Marshall, Geophys. Res. Lett. 27, 2933 (2000)

3. R. F. Keeling, S. R. Shertz, Proc. Natl. Acad. Sci. U.S.A. 99, 7848 (2002).

4. L. Bopp, C. LeQuéré, M. Heimann, A. C. Manning, P. Monfray, Global Biogeochem. Cycles 16, doi: 10.10292001GB001445 (2002).

Our deployment took place in the central Labrador Sea, a region of deep convection subject to strong interannual and interdecadal variability (6). The float measured weekly vertical profiles of $T, S$, and $\mathrm{O}_{2}$ in the upper $2000 \mathrm{~m}$ and remained in the gyre during the fall, winter, and spring (Fig. 1A), i.e., over a full deep convection event. $\mathrm{O}_{2}$ profiles (Fig. 1B) as well as $T$ and $S$ data (not shown) revealed the transition from a late-summer stratified water column (with a mixed-layer depth of $<50 \mathrm{~m}$ ) into a convectively overturning, deeply mixed late-winter situation (mixed-layer depth of $\sim 1400 \mathrm{~m}$ ). This

5. A. Körtzinger, J. Schimanski, U. Send, J. Atmos. Ocean. Technol., in press.

6. R. Curry, M. S. McCartney, J. Phys. Oceanogr. 31, 3374 (2001).

7. H. E. Garcia, R. F. Keeling, J. Geophys. Res. 106, C12, 31155 (2001).

8. Supported by the German Research Foundation through the Sondenforschungsbereich 460 .

9 July 2004; accepted 9 September 2004

Leibniz-Institut für Meereswissenschaften, 24105 Kiel, Germany.

*To whom correspondence should be addressed. E-mail: akoertzinger@ifm-geomar.de 